\title{
Evidence-based health architecture
}

Carlo V Bellieni ${ }^{*}$ and Alessandro Bellieni ${ }^{2}$

${ }^{1}$ University Hospital, Siena (Italy)

${ }^{2}$ Politecnico di Milano, Italy

The "Healthcare Facilities Symposium and Expo" held in Orlando (15-17 November 2016), highlighted the importance of a patientcentered health architecture. Sharing these progresses is imperative.

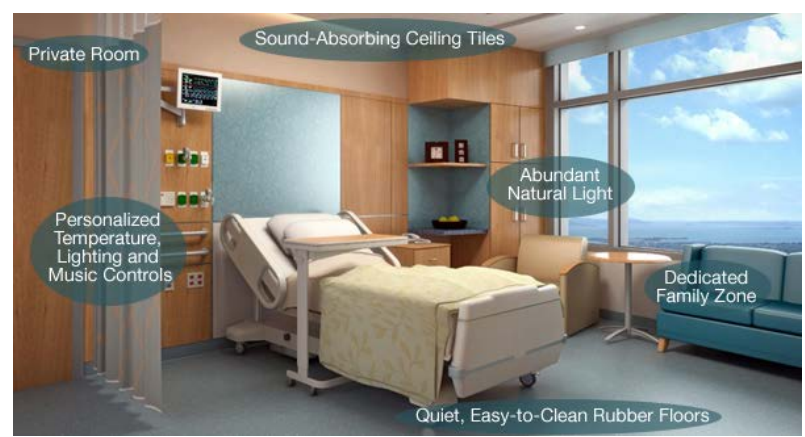

Figure 1. Scientific studies on the effects of the surrounding environment on the patient healing process have been carried out only in the last decades. "Evidence-based design" was introduced in 2003 by health care architect D. Kirk Hamilton as "the process of basing decisions about the built environment on credible research to achieve the best possible outcomes" (Figure 1: UCSF Medical Center at Mission Bay, acute care patient room at the future women's specialty hospital).

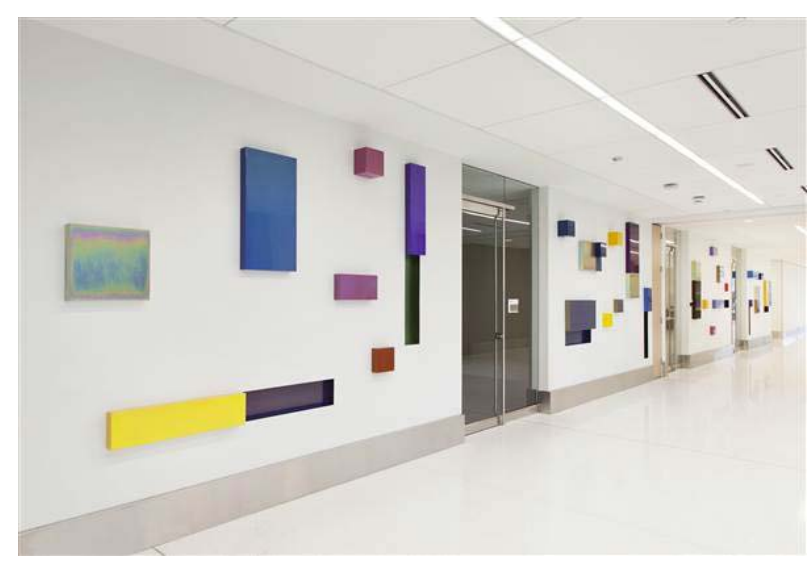

Figure 2. Experiences during the 70s, such as Peter Senior's

Copyright: (C2016 Bellieni CV. This is an open-access article distributed under the terms of the Creative Commons Attribution License, which permits unrestricted use, distribution, and reproduction in any medium, provided the original author and source are credited. experiment of "Arts for Health" in the Wythenshawe Hospital in Manchester or the study of the therapeutic effects of gardens by Claire Cooper Marcus, have provided the basis for the present progress. Nowadays, in US More than 40 percent of health care facilities in 2007 has arts programs, including musical performances, healing gardens and art classes, according to a 2009 report from Arts \& Health Alliance, a Washington, D.C., nonprofit (Figure 2: Margo Sawyer's piece title "Synchronicity of Color" installed in the outpatient building at Eskenazi Health in Indianapolis).
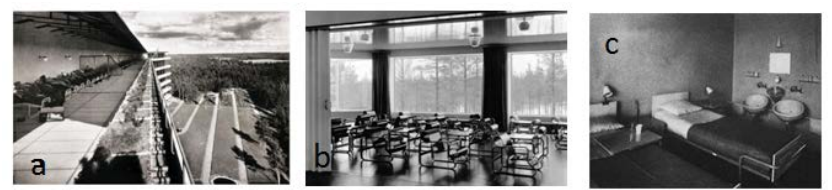

Figure 3. The importance of architecture as a "Medical Instrument" was pioneered by Finnish architect Alvar Aalto, when in 1929 he designed the UNESCO world heritage Tuberculosis Sanatorium in Paimio, at deep contact with nature (a) creating specific ergonomic chairs for patients (b) and patient-tailored rooms (c) Bedrooms held two patients, each with his or her own cupboard and washbasin (see here special noiseless non-splash basins). Since the patients spent many hours lying down, Aalto placed the lamps in the room out of the patients' line of vision and painted the ceiling a relaxing dark green so as to avoid glare.

Correspondence to: Carlo Valerio Bellieni, Medical Director, Department of Pediatrics,University Hospital, Siena (Italy), Tel: 0039-347 357-4566, Fax: 00390577586182,E-mail: cvbellieni@gmail.com

Received: November 14, 2016; Accepted: November 24, 2016; Published: November 28, 2016 